\title{
Exploring ARAC Support of U.S. Coast Guard Planning and Response Capability
}

M.S. Baker, R.L. Baskett, and J.S. Ellis

\section{July 1, 2001}

U.S. Department of Energy

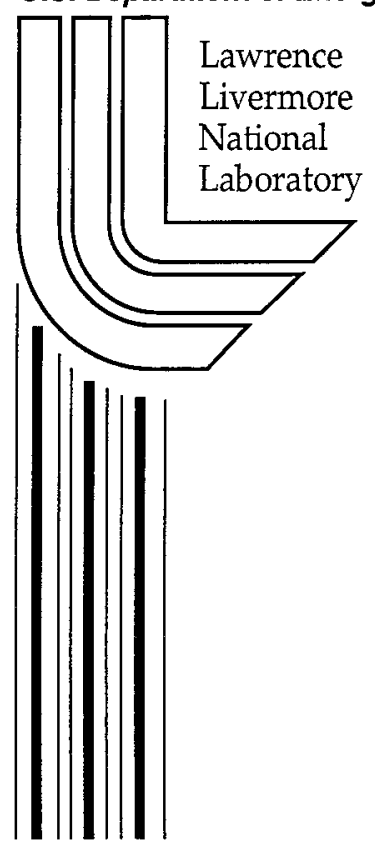




\section{DISCLAIMER}

This document was prepared as an account of work sponsored by an agency of the United States Government. Neither the United States Government nor the University of California nor any of their employees, makes any warranty, express or implied, or assumes any legal liability or responsibility for the accuracy, completeness, or usefulness of any information, apparatus, product, or process disclosed, or represents that its use would not infringe privately owned rights. Reference herein to any specific commercial product, process, or service by trade name, trademark, manufacturer, or otherwise, does not necessarily constitute or imply its endorsement, recommendation, or favoring by the United States Government or the University of California. The views and opinions of authors expressed herein do not necessarily state or reflect those of the United States Government or the University of California, and shall not be used for advertising or product endorsement purposes.

This work was performed under the auspices of the U.S. Department of Energy by the University of California, Lawrence Livermore National Laboratory under Contract No. W-7405-Eng-48.

This report has been reproduced

directly from the best available copy.

Available to DOE and DOE contractors from the

Office of Scientific and Technical Information

P.O. Box 62, Oak Ridge, TN 37831

Prices available from (423) 576-8401

http://apollo.osti.gov/bridge/

Available to the public from the

National Technical Information Service

U.S. Department of Commerce

5285 Port Royal Rd.,

Springfield, VA 22161

http://www.ntis.gov/

OR

Lawrence Livermore National Laboratory

Technical Information Department's Digital Library

http://www.llnl.gov/tid/Library.html 


\section{Exploring ARAC Support of U.S. Coast Guard Planning \& Response Capability}

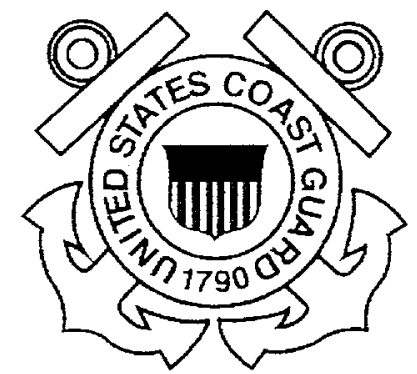

1/c Matthew S. Baker United States Coast Guard Academy 7038 Chase Hall

New London, CT 06320

(860) 444-8294

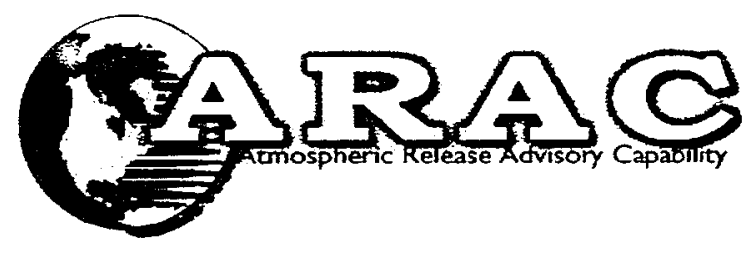

Ronald L. Baskett James S. Ellis Atmospheric Release Advisory Capability Lawrence Livermore National Laboratory

P.O. Box 808, L-103

Livermore, CA 94551

(925) 422-1867

\section{ABSTRACT}

The Atmospheric Release Advisory Capability (ARAC) is a powerful computer modeling system that can quickly predict the consequences of atmospheric releases of hazardous material. The U.S. Coast Guard, responsible for responding to hazardous material spills in the marine environment, relies on other agencies for atmospheric modeling support. The ARAC system could provide the USCG with a powerful yet easy to use resource that could make planning and response operations more effective. 


\section{Introduction}

The U.S. Coast Guard is responsible for the protection of the marine environment from spills of oil and hazardous material. The USCG responsibilities include responding to oil and chemical spills from ships as well as from sources ashore. While responding to a spill, The USCG Marine Safety Offices and Detachments, and the National Strike Force (NSF) depend on interagency support from the Environmental Protection Agency (EPA), National Oceanic and Atmospheric Administration (NOAA), and state and local agencies. Currently, the USCG depends on NOAA Scientific Support Coordinators for predicting and assessing atmospheric releases of hazardous material. NOAA has several computer models that the Coast Guard can access in the event of a chemical release into the atmosphere or an in situ oil burn. However, the Department of Energy operates a more powerful modeling system called the Atmospheric Release Advisory Capability (ARAC). Located at the Lawrence Livermore National Laboratory in Livermore, California, ARAC offers a complex multiscale model in a system that is simple for the end user to operate. The applicability of ARAC to Coast Guard operations is the subject of this study.

\section{Coast Guard missions involving atmospheric releases}

\section{A. In situ burning of oil}

When the conditions are favorable, burning spilled oil in place is a viable way of removing it from the marine environment. The problem is that the fire creates a large plume of smoke. If the plume were to drift over a populated area, public safety would be at risk. A dispersion modeling system coupled with a weather forecast can predict the path of the smoke plume and the resulting ground concentration of particulates. The use of a model allows the On Scene Commander (OSC) to know where the smoke plume will go and what the possible public safety risks are before the oil is ignited.

\section{B. Industrial chemical spills}

The Coast Guard responds to hazardous chemical spills in the marine and terrestrial environments. Inland response by the USCG is coordinated with the EPA. Most of these spills involve some release of gas or aerosol into the atmosphere, and many are large enough to threaten public safety on a regional level. Responders to these types of spills benefit from an atmospheric modeling program so that response efforts can be properly directed and the public notified of the risk.

\section{Weapons of mass destruction response}

The Coast Guard's role in the new National Domestic Preparedness Office focuses on responding to terrorist acts involving chemical agents near the coast. The Coast Guard MSO Captain of the Port will assume Federal On Scene Commander duties for coastal areas and will therefore be in charge of the response to a chemical agent attack (CONPLAN section I.5). An atmospheric modeling program will be a key tool to assist in public safety. 


\section{The Coast Guard's current atmospheric modeling capability}

The Coast Guard currently relies on NOAA for atmospheric modeling. NOAA has created several models that are used in spill response and planning in a package known as CAMEO (Computer Aid Management of Emergency Operations). CAMEO contains ALOHA (Areal Locations of Hazardous Atmospheres), an atmospheric dispersion modeling program; and MARPLOT (Mapping Application for Response and Planning), a graphical mapping program. These programs are operated by NOAA's Scientific Support Coordinators (SSCs), who are each responsible for the application of NOAA response technologies in a specific region. When atmospheric modeling is needed, the Coast Guard Federal On Scene Coordinator calls the NOAA SSC with the information about the spill or release. The SSC runs the programs and returns the information back to the Coast Guard over the phone or in person (E. Levine, personal communication). NOAA has also used ALOFT, a model created by the National Institute for Standards and Technology's Fire Research Lab specifically for fires (D. Walton, personal communication).

\section{A. CAMEO}

NOAA created the CAMEO package to provide first responders with detailed information about hazardous materials and allow them to create contingency plans for hazardous material releases. Aside from the separate ALOHA and MARPLOT applications, CAMEO consists of many different modules. The primary module is a chemical database that lists critical information about more than 4000 chemicals. Other modules include the storage and transportation of chemicals, incident plans and contacts information. There is also a site-mapping program that allows users to create maps of their facilities that can be used in hazardous material release responses (CAMEO manual).

\section{B. ALOHA}

When a hazardous chemical has been released into the atmosphere as a gas, information can be exported from CAMEO to ALOHA, the atmospheric dispersion modeling program NOAA uses for Coast Guard responses for chemical spills. ALOHA was designed to be used during emergencies, and therefore trades complexity for speed and ease of use. The program's models are simple enough to be run on a personal computer. The user interface was designed to be easy enough for an inexperienced responder to use in a high pressure, emergency situation. ALOHA's simplicity limits it effective use by the Coast Guard. First, without a topography database, it assumes the area of the release to be completely flat. Secondly, it cannot model particulates, buoyant gases, chemical reactions, and fires, meaning that it cannot be used in an in situ burn scenario. Finally, it is limited in the time domain to a 1-hour release (ALOHA manual).

For meteorological data, ALOHA uses inputs of inversion height, wind speed and direction, temperature, ground roughness, cloud cover, and relative humidity. The user chooses an upper air stability class from six standard choices ranging from completely stable to completely unstable. ALOHA can link to a Station for Atmospheric Measurements (SAM) for real-time updates of wind speed and direction, air temperature, and standard deviation of wind direction and stability class. 
The source term is based on user inputs and a database of 947 chemicals. Source term data may be imported directly from CAMEO only if the chemical is in ALOHA's database. ALOHA characterizes the source as a direct release, puddle, tank, or pipe. ALOHA supports variable release rates in two dispersion models, one for neutral gases and one for heavy gases. The neutral gas model is a steady-state Gaussian dispersion model and the heavy gas model simulates the flow along the ground before it is dispersed by atmospheric turbulence.

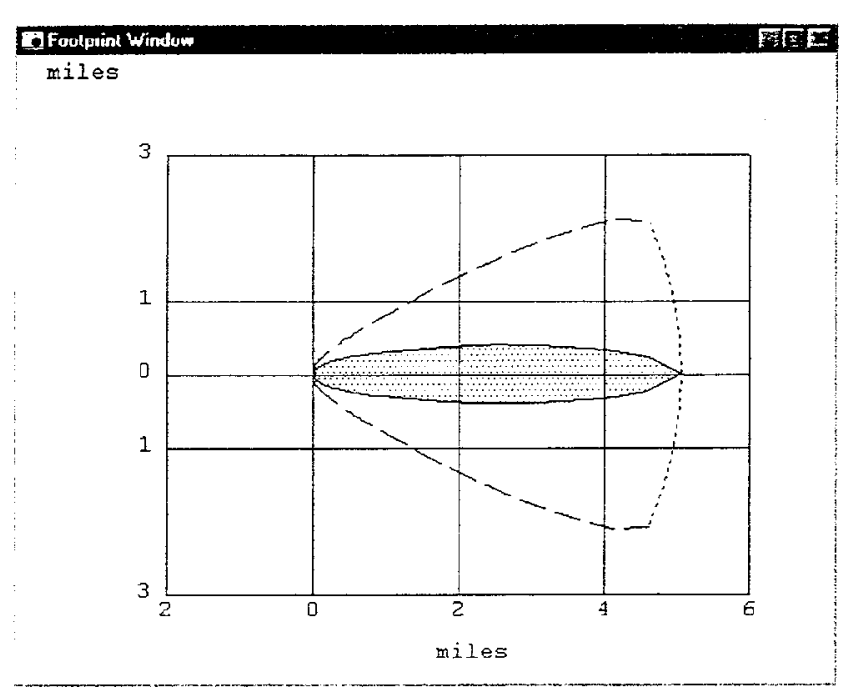

Figure 1: ALOHA footprint plot
The ALOHA dispersion models make several assumptions to model the transport of released material. As a steady state model, it assumes that wind speed and direction are constant in all horizontal directions, and the surface roughness does not change in the entire model area. Additionally, ALOHA assumes that buildings or terrain will not block a vapor cloud. Also, deposition is not allowed during the model run. ALOHA can model resolution as low as 10 meters, but the model domain can not be greater than 10 kilometers

(ALOHA technical description).

ALOHA can output the results of the model in a variety of ways. First is the text summary, which shows all input data as well as the output information in written text. Next is the footprint plot (Figure 1). This plot shows a view of the ground level air concentration, with dashed lines indicating the uncertainty in the calculation. Lastly, three line graph plotting options are available: concentration vs. time, dose vs. time, and source strength vs. time, all at a user-specified point.

NOAA studies are underway to confirm the validity of the ALOHA model by comparing its results to both other models and field data. For comparison to other models, a series of input values that test every calculation ALOHA makes is generated. These values are entered into ALOHA and the older models ARCHIE and CHEMS-PLUS, and the results are compared. The purpose of this phase of the validation is to find errors in the computer code, problems in the model algorithm, and to find what areas of the model need improvement. Comparisons were also made to field data from a series of sulfur dioxide releases in Nebraska in 1956. These trails were conducted on flat, open terrain. A 2 meter wind vector from the release point was used, and trials were conducted at day and night. ALOHA's average predicted values exceeded the actual average by $42 \%$ with the model being the most inaccurate near the release. A test of the heavy gas model component of 


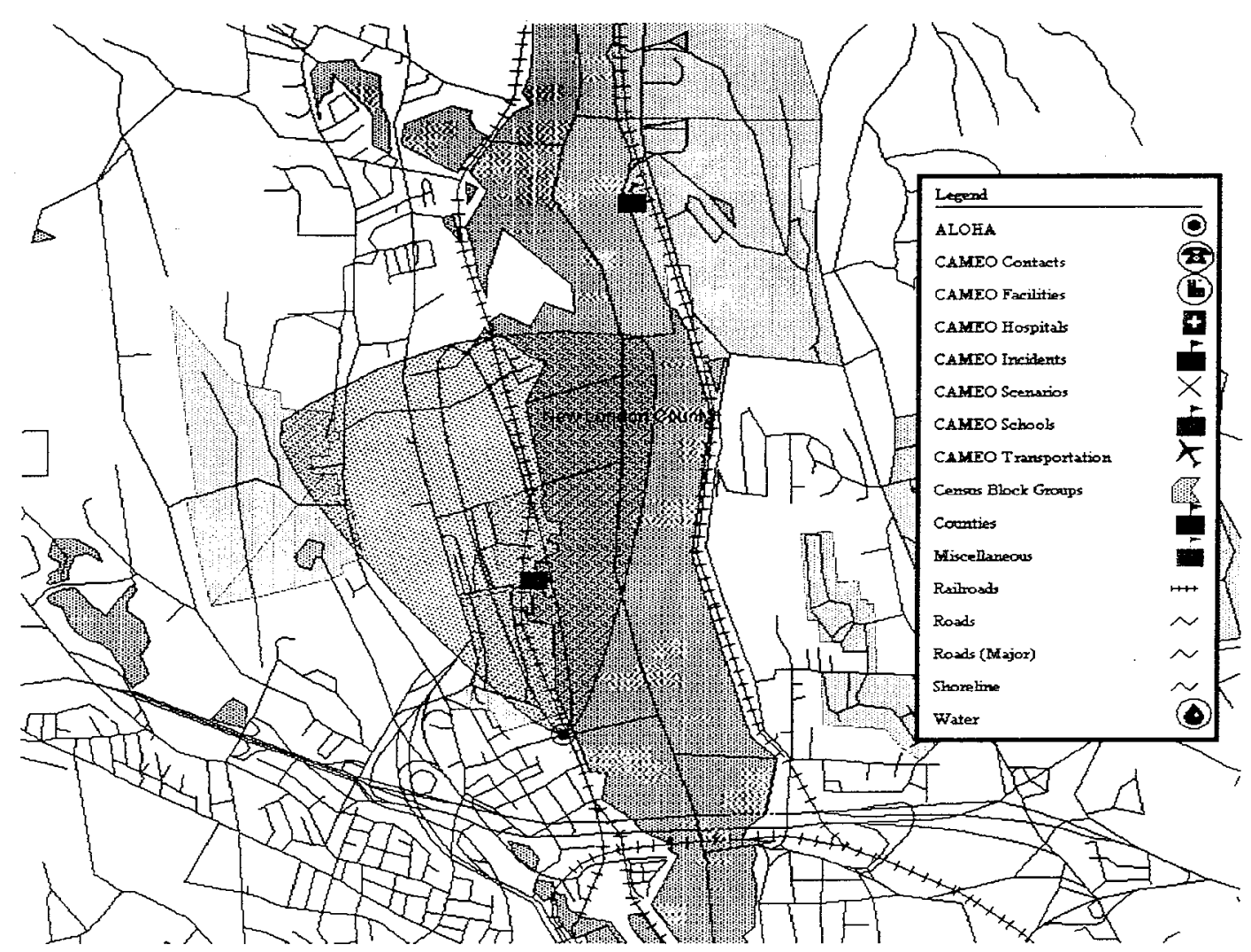

Figure 2: MARPLOT output

ALOHA, with 12 trials, showed predicted values of $107 \% \pm 27 \%$ of the actual values (ALOHA technical description).

\section{MARPLOT}

MARPLOT is a mapping and layering program that can interface with ALOHA. It can read maps from the Bureau of Census Tiger/Line database, so it can cover the entire nation if the user has all the map files. The user can modify these maps to increase the detail of his local area. Once a dispersion model has been run in ALOHA, the plots can be overlaid onto a MARPLOT map (Figure 2). Additionally, by clicking on a location on the map, the user can set the location of the ALOHA source term (MARPLOT manual).

\section{D. $A L O F T$}

ALOFT (A Large Outdoor Fire plume Trajectory) is a numerical model developed specifically to predict the downwind concentrations of smoke and other concentration products for in situ burns. The publicly available version, ALOFT-FT, models flat terrain only, but a complex terrain version exists and can be used for responses. The program has a graphical user interface and produces graphical plots. Figure 3 shows the output summary screen of an ALOFT-FT model run with inputs from the NEW CARISSA incident. The ALOFT-FT version runs on a personal computer and generates results in a few minutes. A new version, ALOFT-CT, models complex terrain. While not publicly available, NIST can run ALOFT-CT at the request of the NOAA SSC (D. Walton, personal communication). 


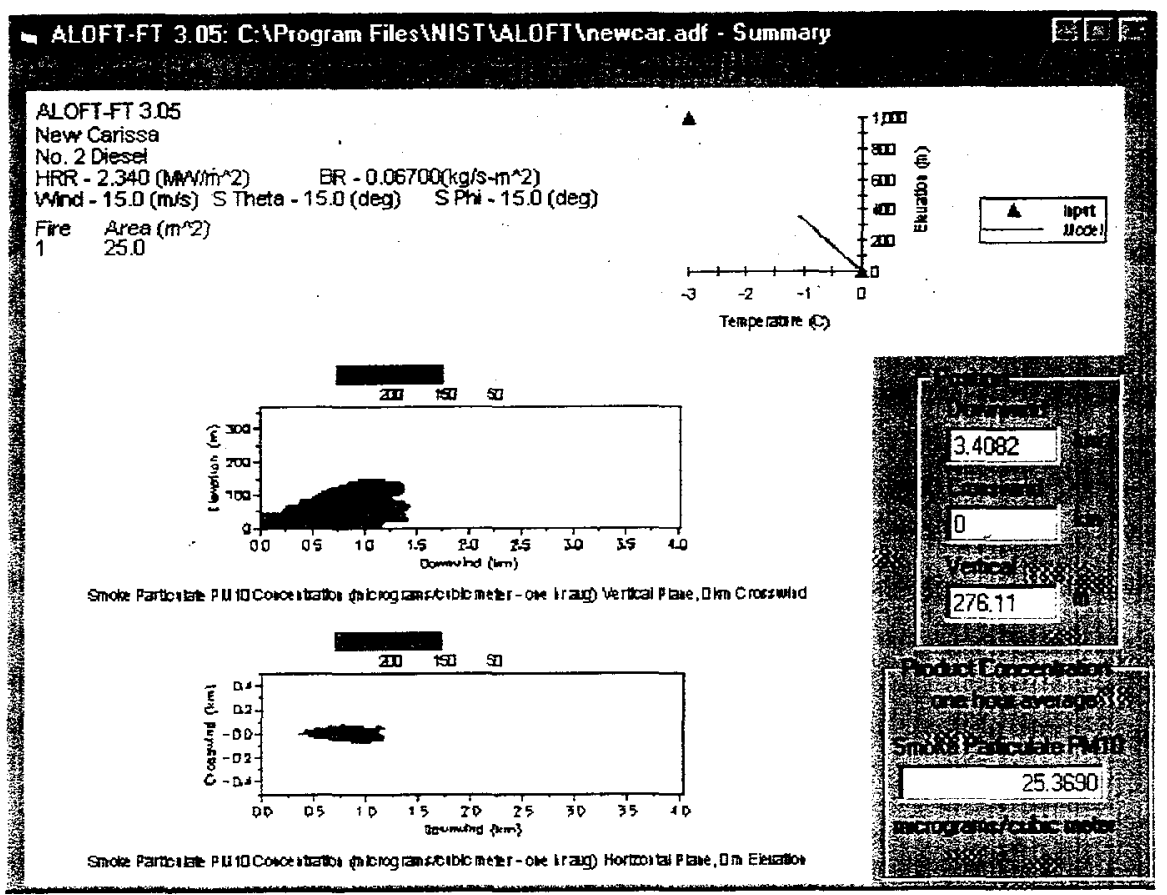

Figure 3: ALOFT-FT output summary

Unlike ALOHA, ALOFT does not use a simple Gaussian dispersion. It actually solves the Navier-Stokes equations (Newtonian equations of fluid motion) with an eddy viscosity. However, a uniform grid is used and meteorological conditions are assumed to be constant throughout the entire model domain. ALOFT models atmospheric stability using one of the six general stability classes, A through F. ALOFT can model multiple source fires, and also allows for detailed input regarding the fuel itself, including emission factors for PM-10, PM-2.5, $\mathrm{CO}_{2}, \mathrm{CO}, \mathrm{SO}_{2}$, and VOC. Also, ALOFT places limits on the model domain the user can use. The downwind range is limited to $20 \mathrm{~km}$, and wind speed must be between $2 \mathrm{~m} / \mathrm{s}$ and $15 \mathrm{~m} / \mathrm{s}$ (McGrattan 1999).

ALOFT has been used in at least one actual case. During the NEW CARISSA incident, the NOAA SSC requested and received several ALOFT model runs. Many runs were made, covering a range of burn sizes and wind conditions. The results of the ALOFT runs assisted incident commanders in their decision to order the in situ burn (D. Walton, personal communication).

\section{The Atmospheric Release Advisory Capability (ARAC)}

The Atmospheric Release Advisory Capability employs a modeling system that can predict atmospheric plumes of a released hazardous material on scales from local to global. Staffed by both meteorologists and computer experts, the ARAC Center is on constant alert. The Center also monitors many remote clients at Department of Energy and Department of Defense sites. The ARAC system is being constantly upgraded and improved, and is currently in its third generation (ARAC-3). 
ARAC was originally designed to make predictions for radiological releases for the Department of Energy. During the 1980s, its mission expanded to include radiological releases from DOD sites, and today ARAC can respond to any kind of atmospheric release anywhere in the world. As outlined in the National Response Plan, ARAC will assist other federal agencies in their planning and response duties for weapons of mass destruction (WMD) cases (Federal Response Plan ESF \#8).

The ARAC modeling process begins when an incident is entered into the system. The minimum input is the time, location, and type of release. This information may be entered either electronically or manually. The electronic method is from a client workstation. In the event of a release, the user enters the information into this workstation, which communicates directly with the ARAC system. In the past, the workstation was a dedicated Sun terminal, but the new client in development is a Java application known as the iClient. The iClient can be loaded onto any PC. Alternately, incidents may be reported to the ARAC Center by phone and information manually entered to a model calculation.

The next step in the modeling process is to collect meteorological data. The ARAC system automatically acquires data from many sources: the U.S. Air Force Weather Agency, the NOAA Domestic Data Plus satellite broadcast, and airport weather stations. In addition, ARAC receives pre-gridded analyses and forecasts from the U.S. Navy Fleet Numerical Meteorological and Oceanographic Center twice a day. Each of the DOE and DOD client sites also have their own dedicated weather tower which provides local observations. In addition, weather observations can be manually entered into the system. This capability allows responders to enter local weather observations from the scene into the model, which increases the accuracy of the model. Once the model is running, surface observations are automatically updated hourly and upper air observations twice a day. The continuous automatic feed of worldwide meteorological data into the ARAC system makes it ready for any release anywhere.

After weather data has been gathered, the system generates terrain in the geographical area of the release. ARAC can generate terrain at any location in the world including over the ocean (the model works just as well over the ocean as it does over land). The geography database has a maximum resolution of 100 meters. A domain is chosen for each model run. As an example, a domain of 20 kilometers means that the model will be run over an area 20 kilometers on each side. The square can be positioned so it is centered over the release site, or offset.

After the domain has been chosen, it is broken up into a grid. This is done by breaking down the square into a specified number of smaller cells. If 50 cells are used on the 20 $\mathrm{km}$ domain, the resultant resolution is 400 meters per cell. The size of the cells is variable, so the cells near the release are smaller than the cells farther away from the release. A vertical grid is also created, using variable resolution, so that the cells are smaller near the ground and larger at the top of the model. Varying the cell size allows for higher precision in the areas where the plume is more likely to be. 

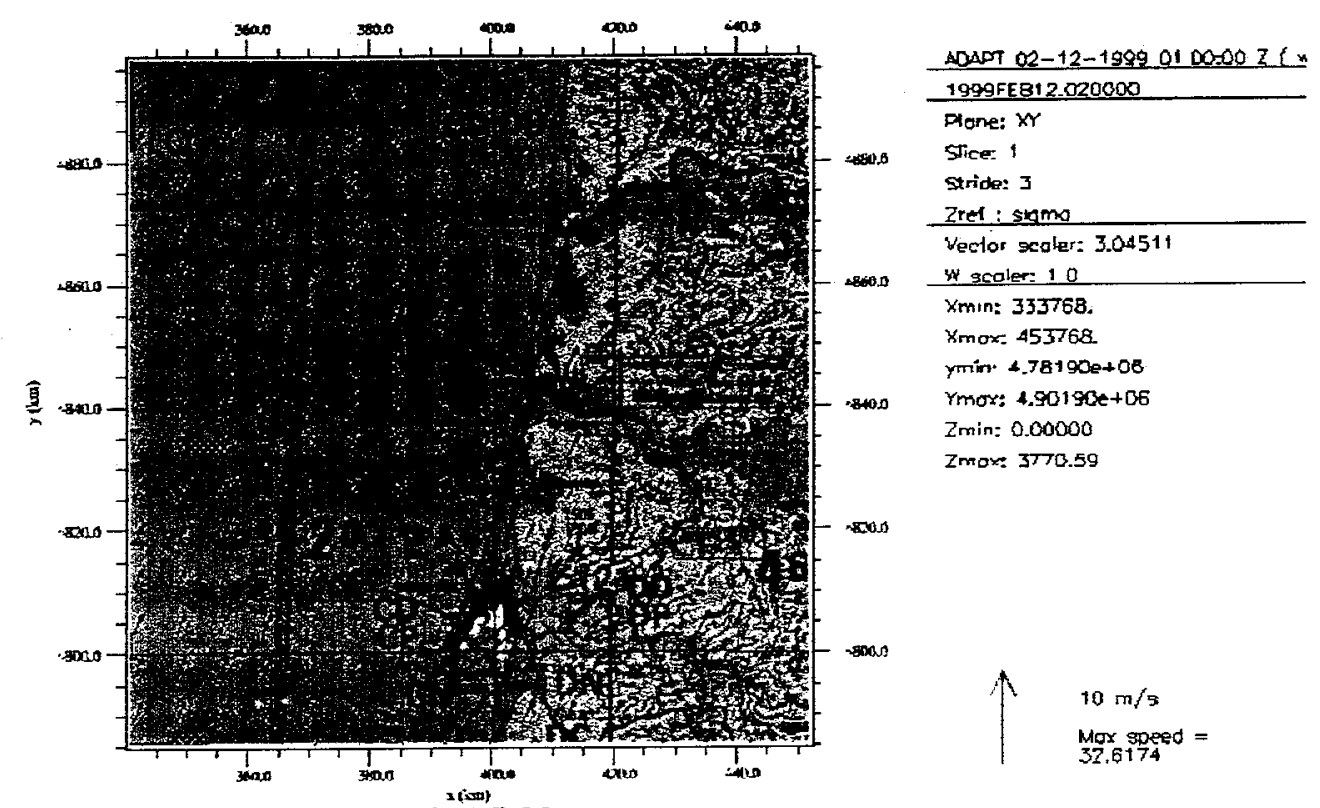

Figure 4: ADAPT wind field

The next step is to grid the observations into the domain so the dispersion model can use them. A program called ADAPT places the point sources in the domain and interpolates among the points so that the entire model domain has meteorological data. The effects of the terrain are also accounted for in this step. This process occurs in three dimensions, so that a cube of vectors is the final product. These are the vectors that will the model will use to determine the path of the plume (Figure 4).

Determining the source term is the next step in the process. The source term defines the release. The type of release, time, and location is the minimum information required, but ARAC is capable of handling many more source term parameters. A range of source geometries, release mechanisms such as spill, fire or explosion, time-varying releases, multiple sources, mixtures, and even moving sources can all be modeled. ARAC is flexible enough to be able to model nearly any material that can be released into the atmosphere. Historically, nuclides, hazardous chemicals, smoke, and volcanic ash have all been modeled. If the amount and duration of the release are known, this information can also be used. Wet and dry deposition rates can be entered to determine removal of the cloud as it moves downwind.

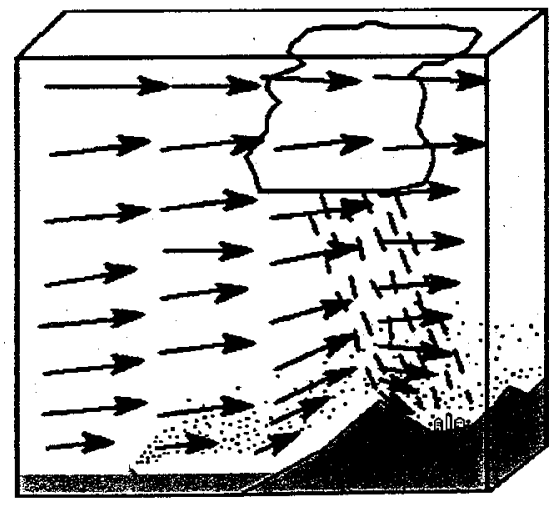

The next step is to run the dispersion model program, called LODI (Livermore Operational Dispersion Integrator), which models the plume using particles. These marker particles are released into the threedimensional gridded vector field at a rate related to the actual rate of release. As each marker particle enters the vector field, forces act upon it and cause it to move. The number of marker particles used determines the resolution of the dispersion calculation. Typically tens of thousands of particles

Figure 5: LODI sketch 
are used for each source. The model tracks the movement of all of the marker particles (Figure 5). After LODI has finished, the results of the model run are saved. The user can then use the data to generate plots.

Plots showing nearly any aspect of the plume can be generated. The plots can be superimposed over raster charts (digitally scanned versions of paper charts), GIS electronic maps (Figure 7), or even satellite photographs of the release site, so that responders can best visualize the release consequences. In addition to the geographic information that can be added, dose and toxicity information is added to provide the user with an explanation of the significance of the concentrations on the plot. These plots are delivered to the remote user electronically, either though the iClient software (Figure 6) or on a private web page (Figure 7). The end user can have these plots in as little as twenty minutes from the time that the incident is reported.

The ARAC system has capabilities beyond the delivery of a plot based on dispersion modeling alone. ARAC can apply real time observations and measurements of the plume back into the model to improve the results in subsequent runs. Together with the capability to add up to date weather information, this allows the ARAC model to be continuously tweaked by the assessors in order to produce the most accurate results.

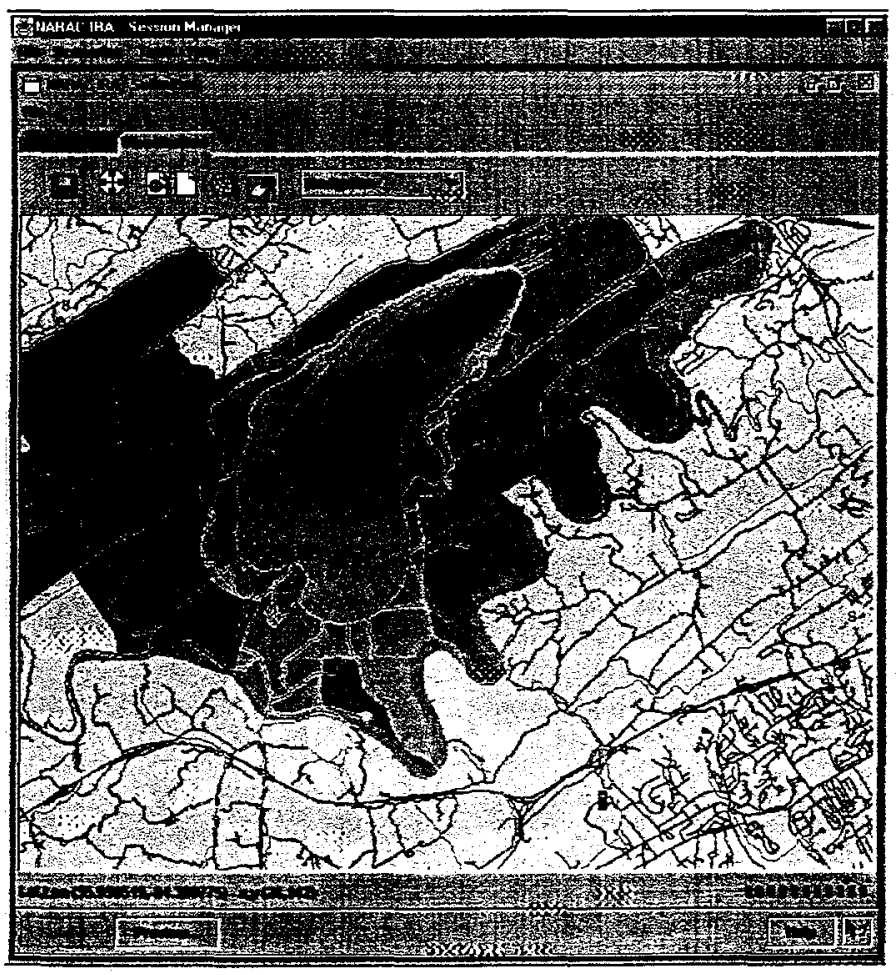

Figure 6: iClient plot display

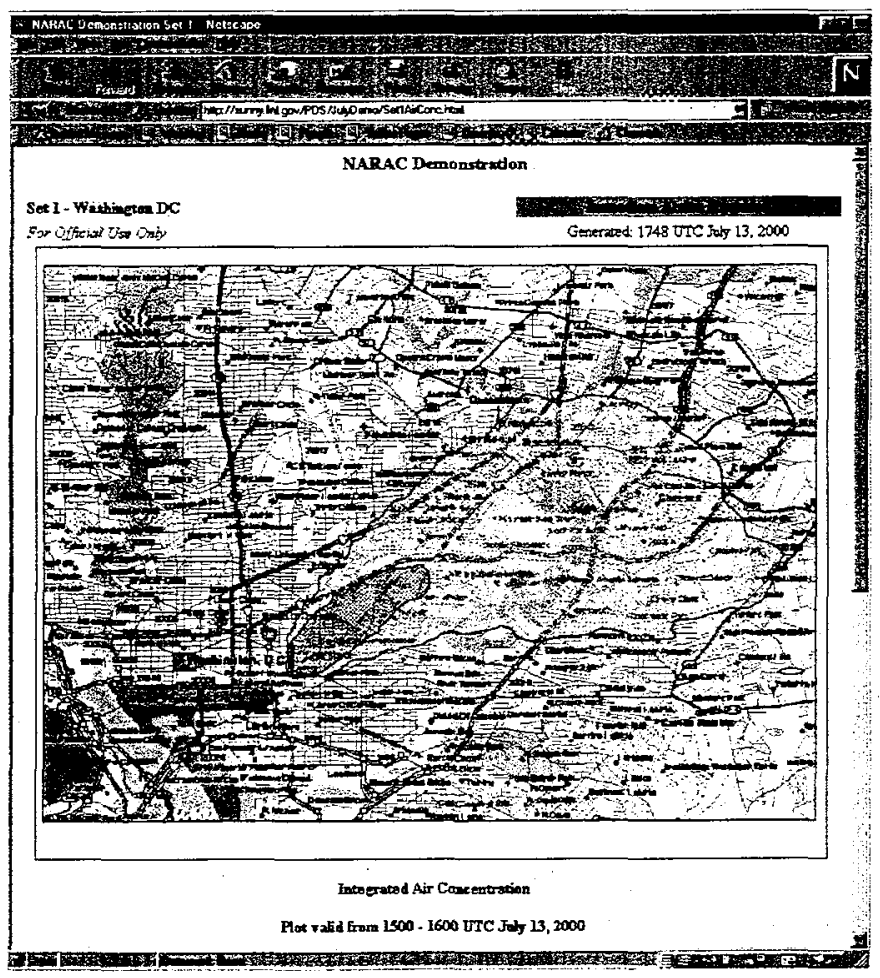

Figure 7: Plot with GIS map published to web page 


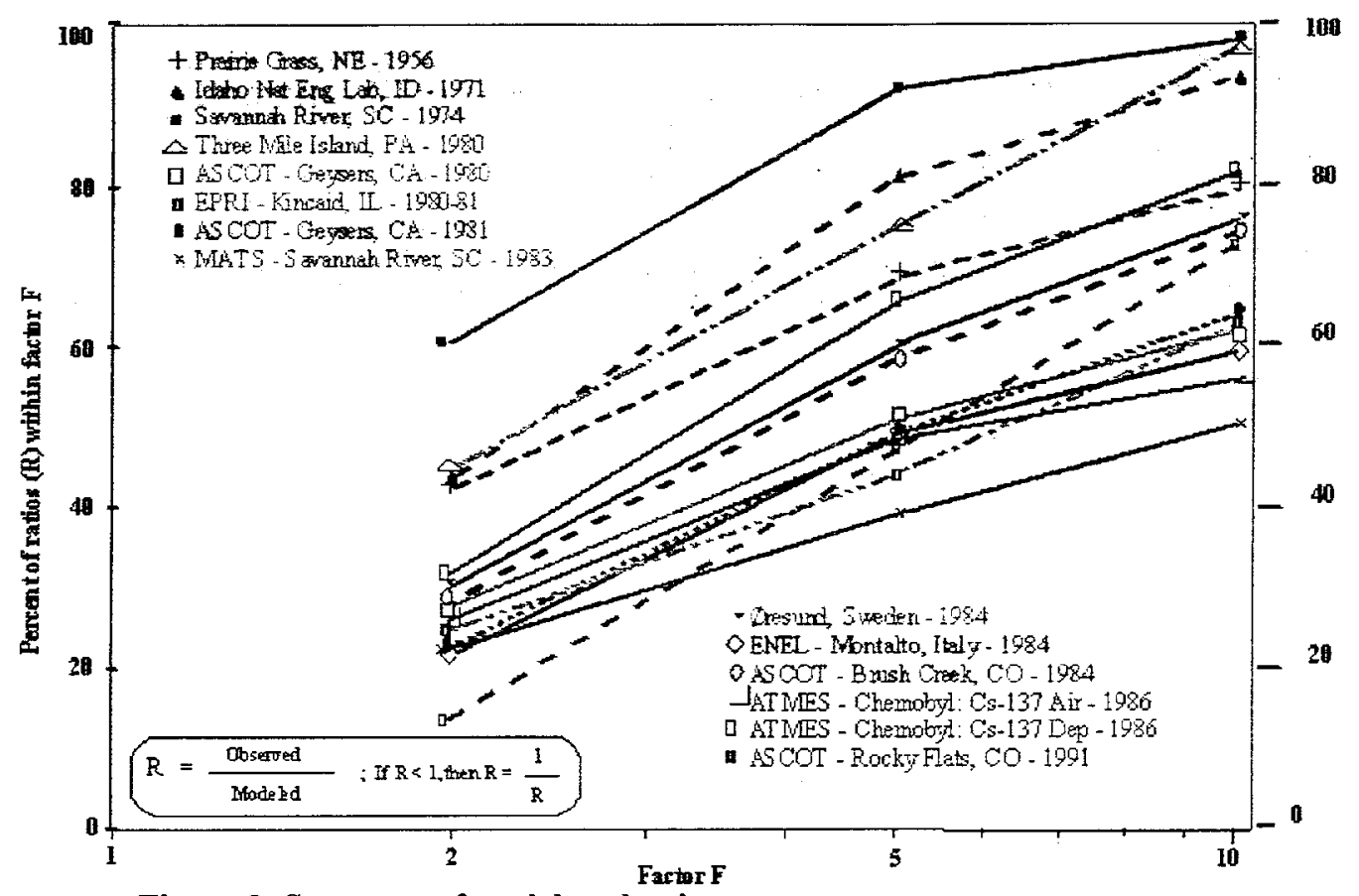

Figure 8: Summary of model evaluations

\section{ARAC model evaluation}

Numerous studies of the accuracy of the ARAC model have been made. These studies were conducted by releasing tracer particles into the atmosphere, monitoring their movement at downwind stations, and comparing the results to ARAC model predictions. Release mechanisms, meteorology and topographical conditions have varied throughout the tests. Neutrally and positively buoyant (explosively released) tracers have been used.

The statistical method used for presenting the results of these evaluations involves determining how often the ARAC model prediction is within a certain factor $F$ of the actual value. The plot in figure 8 shows the history of evaluations. The plot shows the percentage of ARAC predictions at points within the plume that are within the factor F. All measurements along the plume centerline and on the plume edges were included in each study, making the ARAC model one of the most rigorously evaluated in the world (Foster 1990).

\section{Applicability of ARAC to Coast Guard missions}

\section{A. In situ burns}

The ARAC modeling system is capable of modeling a release with a positively buoyant source term such as a fire. The system has already been successfully used in the 1991 Kuwaiti oil fires (Sullivan et al. 1993) as well as several recent tire dump fires in California (Baskett 2000). For a Coast Guard in situ burn operation, ARAC could be notified of the possible burn scenario and generate plots using real time weather data. 
ARAC assessors (all meteorologists) can also use weather forecasts to make predictions about the plume in the future. The ARAC plots can provide response leaders a high level of confidence when considering an in situ burn. Additionally, while the burn is being conducted, ARAC can be used in conjunction with the Coast Guard's SMART (Special Monitoring of Applied Response Technologies) program for in situ burns. Unlike other modeling systems, ARAC is capable of entering data gathered by SMART teams back into the model after the initial run. This allows ARAC assessors to adjust the parameters of the model run so that the results can be improved, providing response leaders with constantly updated information about the atmospheric plume.

\section{B. Hazardous chemical spills}

In the past, the ARAC system has been used to effectively model numerous chemical releases. One example involving a Coast Guard response was a release of oleum from a tank car in Richmond, California. The ARAC team successfully modeled a plume of sulfuric acid mist, providing enough warning for public health officials to take action to protect the population (Baskett et al. 1993). Coast Guard Strike Teams are faced with responding to similar releases along the coast as well as inland. ARAC can be used to determine whether or not to warn the public and to protect the responders.

\section{Weapons of mass destruction response}

The ARAC system can be used to model the release of any weapon of mass destruction, whether chemical, biological, or radiological. To aid responders to acts of terrorism, ARAC can support moving release sources such as trucks or airplanes. Under the U.S. Federal Response Plan, the U.S. Coast Guard is a leading response agency for hazardous material releases due to terrorism. Coast Guard responders will be activated in a chemical release (FRP ESF \#10). ARAC plume predictions can be a valuable tool that improves the effectiveness of the response and increases the safety of the responders and the public.

\section{Planning}

In addition to response missions, Coast Guard Marine Safety Offices are responsible for planning for potential hazardous material releases in their area of responsibility. The ARAC system and its iClient software under development can provide a tool to aid in planning. MSO planners can create potential release scenarios in the iClient software. If there is a chemical plant in the AOR that stores chemical X, the planner can create a scenario with a source term for a release of chemical $\mathrm{X}$ at the location of the plant. Information about the source, such as the tank capacity, can also be stored. This scenario can be saved, and if an actual release occurs, the MSO only needs to open the scenario to make any adjustments needed. It would then be sent to the ARAC center, where modeling with current meteorological data takes place. The planning feature of the iClient software allows the system to deliver fast and accurate plots, giving responders a head start. 


\section{ARAC implementation process}

ARAC can be implemented as a Coast Guard resource soon. The best way to do so would be to install the iClient at response units, like the NSF. The software can be loaded on the existing workstations. Another possibility is to install the client in the Incident Command Center so that on scene commanders can use updated plots throughout the response operation. The iClient can be run on a laptop computer with a cell phone modem, meaning that responders can communicate with the ARAC nearly anywhere in the world. In addition to the computer link, voice communication with the ARAC Center is also possible. The communications can be tested in coordinated drills. The iClient software is provided at no cost. ARAC does not charge for model runs, but does charge an annual use fee by organization for training, readiness, and interactive exercising.

Before ARAC could provide support for the Coast Guard, agreements with the Department of Energy are needed. Coordination between the Coast Guard and the DOE is not unprecedented, and the agencies will be working together more in the future as part of the National Domestic Preparedness Office. In the near future, the Coast Guard will be joining the Emergency Communications Network (ECN), a series of dedicated video conference lines that allow response organizations to communicate at the headquarters level. ARAC and DOE headquarters are already members of the ECN.

\section{ARAC case study: M/V NEW CARISSA}

The M/V NEW CARISSA accident provides a case study to use for examining the capability of the ARAC system. The 639-foot bulk carrier ran aground on a beach north of the entrance to Coos Bay, Oregon, on the morning of February 4, 1999. The ship had been anchored the previous evening, but had dragged anchor due to a severe winter storm. The ship, while not carrying any cargo, had approximately 359,000 gallons of $\# 6$ fuel oil (Bunker C) and 37,400 gallons of \#2 diesel on board. Over the next four days, several attempts to float the ship were unsuccessful. Weather forecasts of severe weather made response personnel face the likelihood that the ship would break apart, spilling the nearly 400,000 gallons of oil onto the beach. The oil had to be removed from the ship, but the heavy surf and high winds were confounding lightering and salvage operations. A plan to use small tanks hoisted by helicopter was also considered but deemed too dangerous. Response leaders concluded that in situ burn was the best response option. The oil could be ignited on board the vessel before it spilled into the environment (FOSC Report 5).

A primary concern with the in situ burn operation would be the effect of the resulting smoke plume on the local towns. Working with the NOAA hazmat team, responders used ALOFT to predict the path of the plume and its resulting ground concentrations of harmful particulate matter smaller than $10 \mu \mathrm{m}$ (PM-10). Several ALOFT runs were conducted to cover a range of atmospheric conditions (D. Walton, personal communication). The model showed little impact on the population, and the in situ burn was approved. The evolution was a success, with approximately 200,000 gallons of oil 
being burned off of the ship and only a small effect on the nearby populated areas (FOSC Report 11).

To illustrate how ARAC could have modeled the NEW CARISSA burn, historical meteorological data and burning oil emission factors were collected. For the meteorological data, A C-MAN station at Cape Arago (only 5 miles south of the NEW CARISSA) was used for surface data, and upper air stations at Medford and Salem were used for aloft data. The emission factors were provided by NIST and were identical to those in the ALOFT program. Information regarding the nature of the oil and the burn itself was gathered from the FOSC report and the SMART NEW CARISSA report written by the Coast Guard, NOAA, the EPA, and the Centers for Disease Control and Prevention.

\section{The ARAC model run}

Hourly observations of surface pressure, temperature, dew point, wind speed and wind direction from Cape Arago were entered, starting at 0000Z on 12FEB99 and ending at $1200 \mathrm{Z}$ on 13FEB99. Upper air observations were entered at $0000 \mathrm{Z}$ and $1200 \mathrm{Z}$ on $12 \mathrm{FEB}$ and $13 \mathrm{FEB}$ for each station. The upper air observations included heights, wind speed and wind direction at mandatory pressures, and the surface observations consisted of wind speed and direction, pressure, temperature, and dew point.

Local terrain was generated on a 300-kilometer square. ARAC assessors usually center the initial terrain on the release site and move it after the first runs so that the plume itself is centered on following runs. For the NEW CARISSA run, the initial terrain was centered. After the terrain was generated, the ADAPT program was run. The one surface

\begin{tabular}{c|c|c} 
Particle & Emission factor $(\mathrm{g} / \mathrm{kg})$ & Total release $(\mathrm{kg})$ \\
\hline $\mathrm{PM}-10$ & 115 & 84,713 \\
$\mathrm{PM}-2.5$ & 85 & 62,614 \\
$\mathrm{SO}_{2}$ & 3 & 2,209
\end{tabular}
station and two upper air soundings were used to interpolate the wind field across the entire domain. Figure 4 shows the interpolated surface wind field at $0000 \mathrm{Z}$ on $12 \mathrm{FEB} 99$,

Table 1 approximately two hours before the burn began.

The source term consisted of three separate releases: PM-10, PM-2.5, and $\mathrm{SO}_{2}$. The ARAC system models each particulate separately, and takes the geometry and size of each particle into account. The total size of the burn was calculated using a total volume of 200,000 gallons (FOSC Report 11) and an oil density of $0.973 \mathrm{~g} / \mathrm{mL}$ at $10^{\circ} \mathrm{C}$ (Environment Canada), resulting in a total mass of $736,638 \mathrm{~kg}$. The NIST emission factors were used to calculate the total mass of each released material (Table 1). Because the fires were burning in the hold of the ship, the buoyant force of the fire was assumed to be lost. The neutrally buoyant plume was generated at an altitude of 27 meters, to simulate the height of the cargo hold. The cargo hatch was assumed to be a circle with a radius of 5 meters (ARAC cannot model a square source geometry).

The NEW CARISSA fire consisted of two segments. Using local time, the main fire started at 1545 on 11 FEB 99 but by 0800 the next morning the only remaining fire was on 


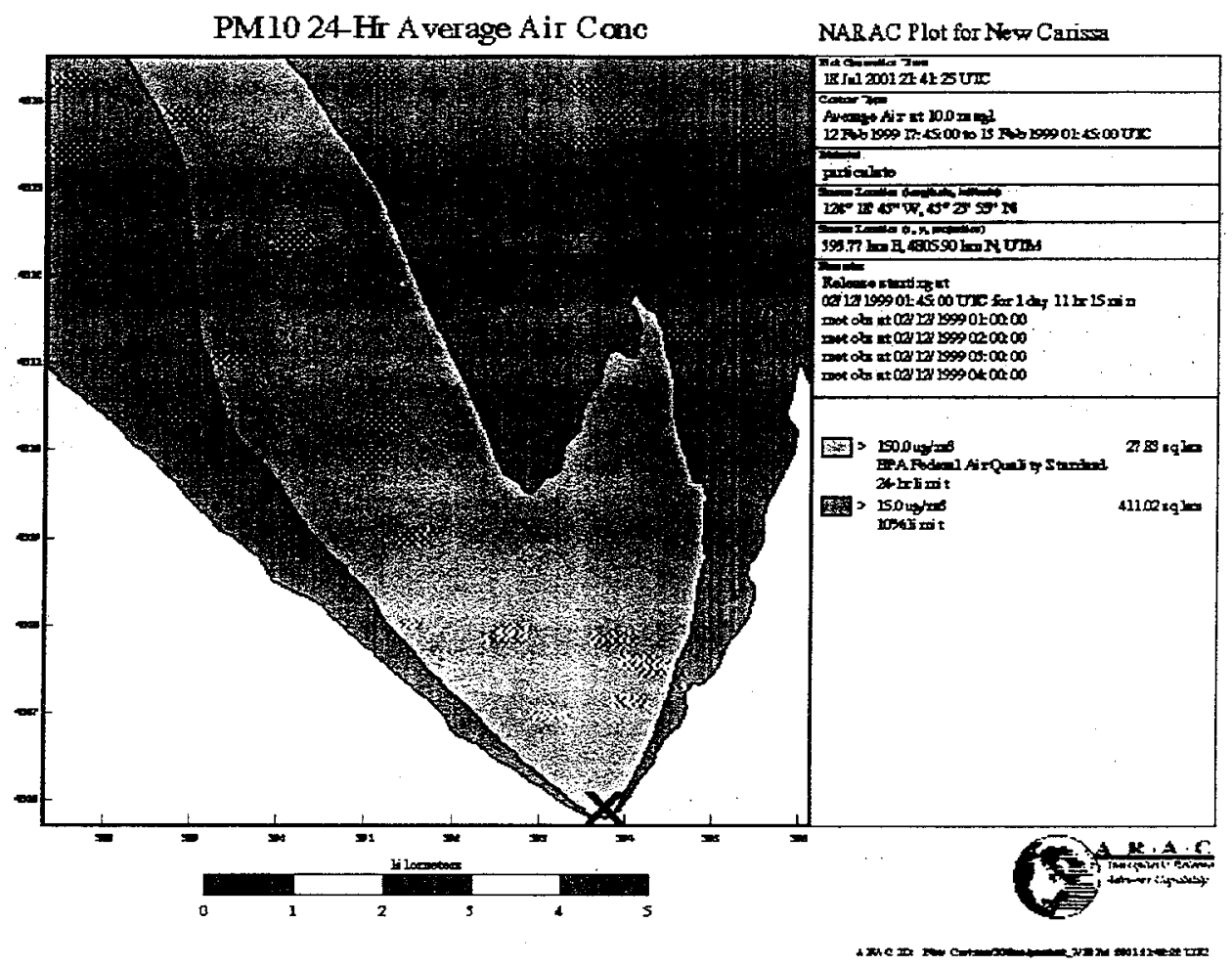

Figure 9: initial PM-10 plot for the NEW CARISSA

the stern section, which burned until 0100 on 13FEB99. To model the varying rate, two release phases were created. The first consisted of releasing $90 \%$ of the material between 1545 on the $11^{\text {th }}$ and 0800 on the $12^{\text {th }}$. The second phase consisted of the remaining $10 \%$ of the material being released until 0100 on the $13^{\text {th }}$. The amount of variability in the release rate is limited only by the number of release phases the assessor enters.

After the meteorological, terrain, and source term data were all entered, the model was run. The model took approximately 15 minutes, after which the assessor produced several plots showing the results. Figure 9 is the first plot produced. It shows the 24 -hour average air concentration 10 meters above the ground for PM-10 for the first day of the fire. The legend on the right side of the plot shows the significance of the contours. The yellow inner area has a concentration greater than $150 \mu \mathrm{g} / \mathrm{m}^{3}$, which is the EPA Federal Air Quality Standard for PM-10 for a 24-hour average. The gray outer area is $10 \%$ of the limit. The plot is oriented north south, but does not yet have geography beneath it.

After the initial plot was produced, geography was added in the form of a raster chart. Several are available, suitable for varying scales. Figure 10 shows four contour plots with raster geography. Plots $10 \mathrm{a}$ and $10 \mathrm{~b}$ show the 24 -hour average air concentration for the first 24 hours of the burn for PM-10 and PM-2.5 on an Operational Navigation Chart (ONC). Plots 10c and 10d show the 24-hour average air concentration for the second 24 hours on a Tactical Pilotage Chart (TPC). Notice that the TPC chart has a larger scale than the ONC. 
(a) PM-10

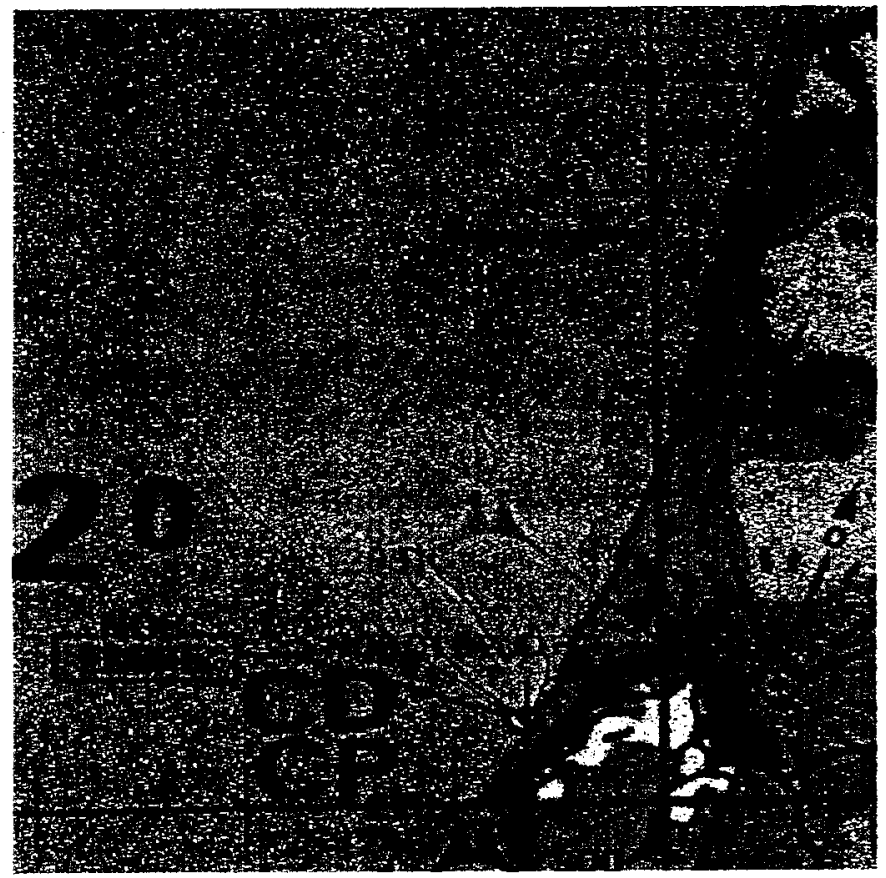

(b) PM-2.5

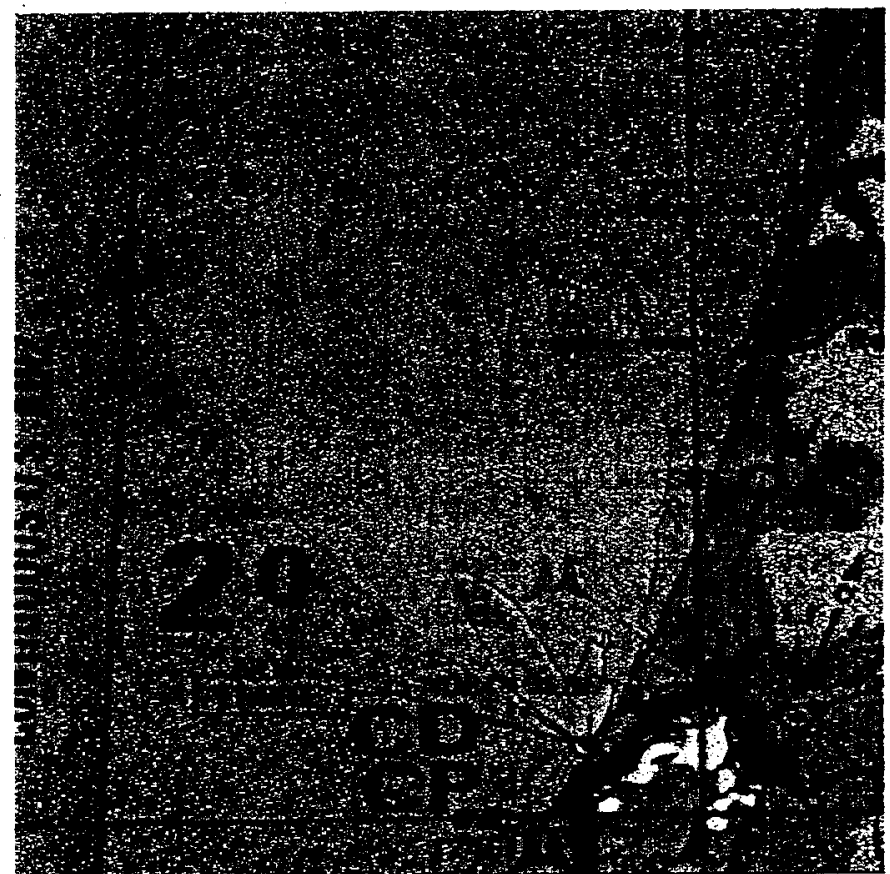

Second 24 hours on TPC geography

(c) PM-10

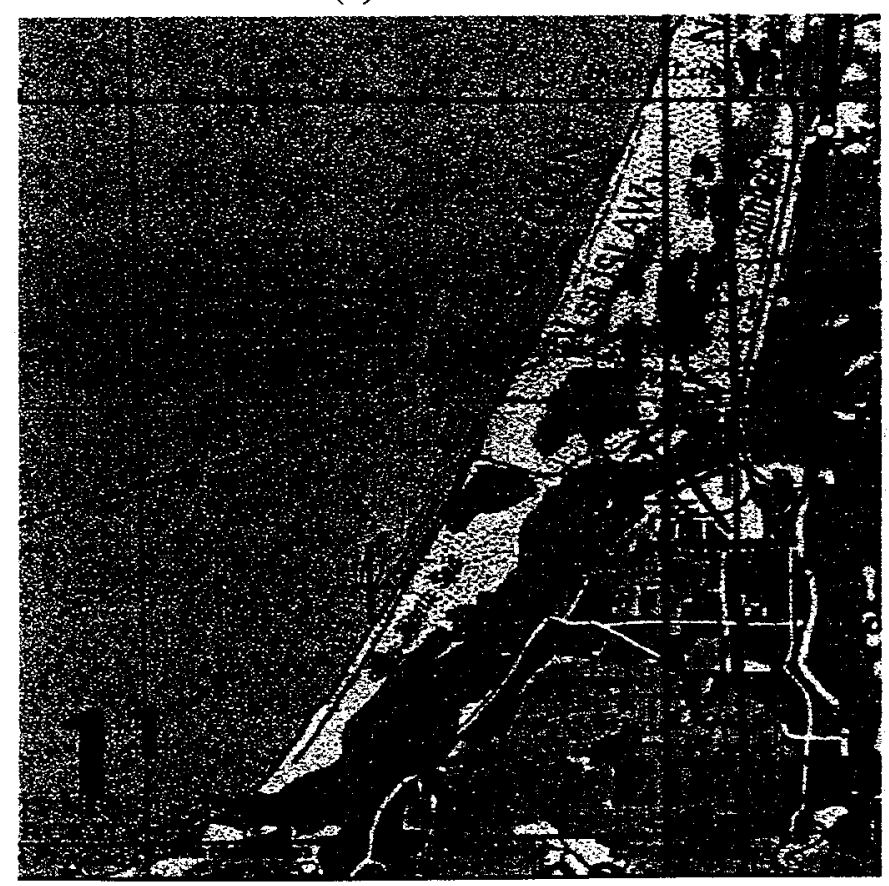

(d) PM-2.5

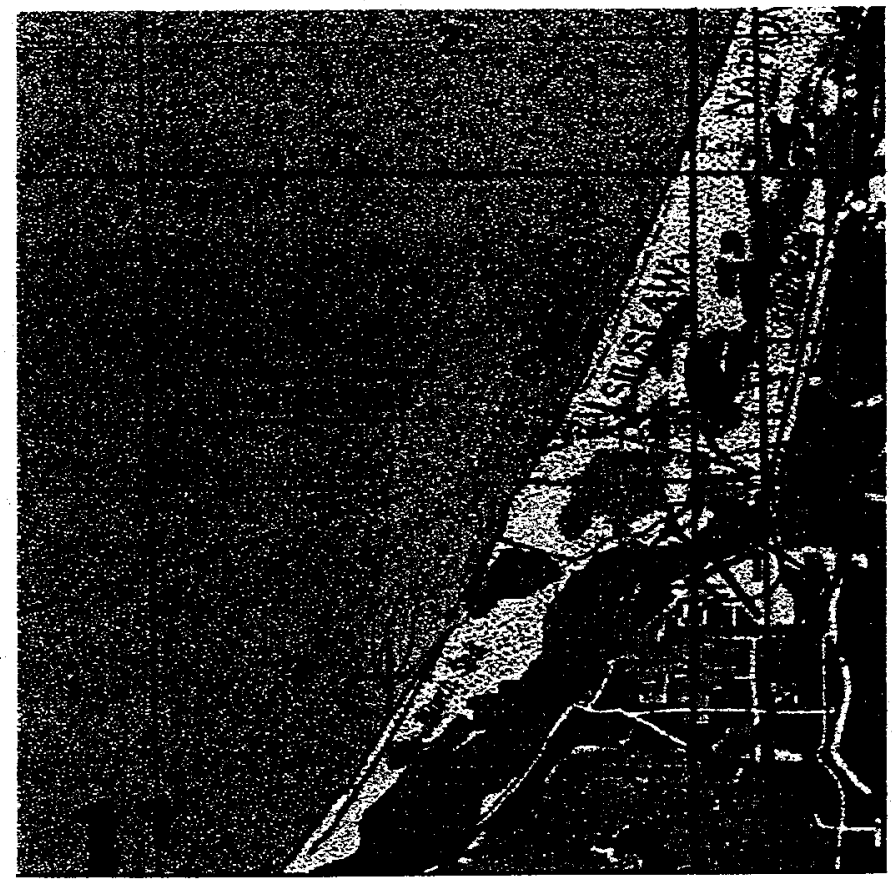

Figure 10: ARAC plots on raster geography 


\section{Conclusions}

The ARAC system could be an excellent tool for Coast Guard M units to use. There are several facts that highlight the advantages ARAC could provide to the Coast Guard:

1. Using a multi-scale, versatile dispersion model, ARAC can successfully simulate any kind of atmospheric release to which a Coast Guard unit could possibly respond to. Because the science behind the models is state of the art ARAC can provide the Coast Guard with the most accurate calculation possible.

2. The planning capability of the iClient software could provide MSOs with a tool to aid in the creation of area contingency plans. These plans would reduce response time to major releases, improving Coast Guard response operations and keeping the public safer.

3. The use of relatively simple iClient software means that Coast Guard personnel would not need to spend time training with dispersion modeling for relatively rare events. The models will be run by experts who perform the task daily.

4. The mobility of the iClient allows it to be in the Incident Command Center or even carried on scene on a laptop computer with a cell modem. ARAC plots can be simultaneously delivered directly to the responders, who need to take immediate action in the field.

5. The communication links through the Internet allow ARAC to deliver detailed information quickly. The direct communication links allow the Coast Guard to work with ARAC directly instead of relying on another agency to act as a go-between for the Coast Guard and the modelers.

6. The ARAC system automatically acquires real time and forecast meteorological data. Automatic collection of meteorological data is an advantage over other models and allows the system to produce results quickly.

7. ARAC personnel are some of the world's foremost experts on atmospheric dispersion modeling. They take their business very seriously and are eager to use their system in more responses. The Coast Guard could rely on them to the fullest as a team member in response operations.

This work was performed under the auspices of the U.S. Department of Energy by the University of California, Lawrence Livermore National Laboratory under Contract No. W-7405-Eng-48. 


\section{References}

ALOHA manual. [Available online from http://www.epa.gov/swercepp/cameo/pubs/aloha.pdf]

Baskett, R.L., Vogt, P.J., Schalk III, W.W., Pobanz, B.M., Foster, C.S., and J.S. Ellis. The Challenge of Emergency Response Dispersion Models on the Meso-Gamma Urban Scale: A Case Study of the July 26, 1993 Oleum Tank Car Spill in Richmond, California, 5 pg

Baskett, R.L., 2000: NARAC Support to the State of California, $10 \mathrm{pg}$

CAMEO manual. [Available online from http://www.epa.gov/swercepp/cameo/pubs/cameowin.pdf]

Chan, S.T., and G. Sugiyama, 1996: A New Model for Generating Mass-Consistent Wind Fields over Continuous Terrain. Preprint, American Nuclear Society's Sixth Topical Meeting on Emergency Preparedness and Response. San Francisco, California, April 22-25, 1997

Chan, S.T., and G. Sugiyama, 1997: A New Meteorological Data Assimilation Model for Real-Time Emergency Response. Preprint, $10^{\text {th }}$ Joint Conference on the Applications of Air Pollution Meteorology with the Air and Waste Management Association. Pheonix, Arizona, January 11-16, 1998

Environment Canada's Environment Technology Centre Oil Properties Database [Available online from http://www.etcentre.org/cgiwin/oil_prop_cgi.exe?Path=|Websitelriver|]

Federal Response Plan. [Available online from http://www.fema.gov/r-n-r/frp/]

Foster, K.T., and M.H. Dickerson, 1990: An Updated Summary of MATHEW/ADPIC Model Evaluation Studies. Preprint, ANS Workshop on Mechanistic Analyses Involving Aerosols in Non-Reactor Facility Accidents. Salt Lake City, Utah, August 2-3, 1990

Foster, K.T., 1995: The Design and Implementation of an Operational Model Evaluation System. Preprint, Ninth Joint Conference on the Applications of Air Pollution Meteorology, Atlanta, GA, January 28-February 2, 1996

Leone Jr, J.M., Nasstrom, J.S., Maddix, D.M., 1996: A First Look at the New ARAC Dispersion Model. Preprint, American Nuclear Society's Sixth Topical Meeting on Emergency Preparedness and Response. San Francisco, California, April 22-25, 1997 
MARPLOT manual. [Available online from

http://www.epa.gov/swercepp/cameo/pubs/marplot.pdf]

McGrattan, K.B., 1999: Smoke Plume Trajectory Modeling. Proceedings, National Institute of Standards and Technology and Minerals Management Service, New Orleans, Louisiana, 75-86

NOAA, cited 2001: Aloha Technical Description. [Available online from http://response.restoration.noaa.gov/cameo/alotech/alotech.html]

Sullivan, T.J., Ellis J.S., Foster C.S., Foster, K.T, Baskett, R.L., Nasstrom, J.S., and W. W. Schalk III, 1993: Atmospheric Release Advisory Capability: Real-Time Modeling of Airborne Hazardous Materials. Bulletin of the American Meteorological Society, 74, 2343-2361

United States Government Interagency Domestic Terrorism Concept of Operations Plan, January 2001. [Available online from http://www.fema.gov/r-n-r/conplan/]

U.S. Coast Guard. NEW CARISSA One Man Formal Investigation, 16SEP99

U.S. Coast Guard. NEW CARISSA POLREP 9, 9FEB99

U.S. Coast Guard. NEW CARISSA POLREP 10, 10FEB99

U.S. Coast Guard. NEW CARISSA POLREP 11, 10FEB99

U.S. Coast Guard. NEW CARISSA POLREP 12, 12 FEB99

U.S. Coast Guard. Federal On Scene Coordinators Report and Assessment of the M/V NEW CARISSA Oil Spill Response, June 1999

National Oceanic \& Atmospheric Administration, U.S. Environmental Protection Agency, U.S. Coast Guard. SMART at the NEW CARISSA Oil Spill, February 2001

Vogt, P.J., Pobanz, B.M., Aluzzi, F. J., Baskett, R.L., Sullivan, T.J., 1999: ARAC Simulation of the Algeciras, Spain Steel Mill Cs-137 Release. ANS $7^{\text {th }}$ Topical Meeting on Emergency Preparedness and Response, Sante Fe, NM 